\title{
O VELHO E O NOVO BANDUNG NA CONJUNTURA DO SISTEMA MUNDIAL
}

\author{
Jales Dantas da Costa'
}

\section{Resumo}

Apresentamos neste artigo a recente Declaração Conjunta de Santa Cruz do G77 e China, destacando recordações, prioridades, registros de avanços e comprometimentos futuros, mas também as graves deficiências no cumprimento dos objetivos do Grupo assim como seus desafios e preocupações atuais. Sabemos que muitos desses desafios e preocupações não são novos, pois já estavam presentes na Conferência de Bandung e mesmo antes. $\mathrm{O}$ que aqui propomos é destacar tanto os motivos do surgimento e enfraquecimento do velho Bandung como debater as potencialidades que um novo Bandung apresenta aos povos do Sul. Para tanto, analisaremos o velho e o novo Bandung no contexto conjuntural do sistema mundial, sobretudo com base nos estudos de Giovanni Arrighi sobre a ascensão e transição da hegemonia norte-americana, e sobre a ascensão chinesa diante do fracasso do "novo programa imperial" dos Estados Unidos.

Palavras-Chaves: hegemonia mundial estadunidense; velho e novo Bandung; ascensão chinesa; G77 e China.

Classificação J.E.L.: F50

Afirmamos que el siglo XXI es el momento para que los Países y los Pueblos del Sur desarrollen sus economías y sociedades a fin de cumplir las necesidades humanas de manera sostenible, en armonía con la naturaleza y respetando a la Madre Tierra y sus ecosistemas. Convenimos en consolidar nuestros valores

Professor do Departamento de Relações Internacionais da Universidade Federal da Paraíba (UFPB). Doutor em Ciências Sociais pela Universidade de Brasília e pesquisador do Grupo de Pesquisa em Economia Política dos Sistemas-mundo. Registro que boa parte do conteúdo desse artigo foi não apenas sugerido como debatido com Daniel Antiquera, também professor da UFPB. E-mail: jalesdc@gmail.com 
tradicionales y las prácticas de solidaridad y colaboración en benefício mutuo y la fortaleza de nuestro pueblo, a fin de lograr progresos en nuestros países y en la cooperación SurSur. (Declaración Conjunta del G77 más China en Santa Cruz de la Sierra, 15/06/2014)

A tentativa norte-americana de reverter a transferência de poder para o Sul global saiu pela culatra. Ela precipitou (...) [a] "crise terminal" da hegemonia norte-americana (...) A dominação ocidental pode se repetir de maneiras mais sutis que no passado e, acima de tudo, ainda há a possibilidade de um longo período de violência crescente e caos mundial interminável. A ordem ou a desordem mundial que acabará por se produzir depende em boa parte da capacidade dos Estados mais populosos do Sul, em primeiro lugar a China e a Índia [acrescentemos a Rússia, o Brasil e a África do Sul para tomarmos o conjunto dos BRICS] de abrir para si e para o mundo um caminho de desenvolvimento mais igualitário em termos sociais e mais sustentável em termos ecológicos do que o caminho que enriqueceu o Ocidente. (Giovanni Arrighi)

\section{INTRODUÇÃO}

Entre os dias 14 e 15 de junho de 2014 foi realizada em Santa Cruz de la Sierra (Bolívia) a Cúpula do Grupo dos 77 países em desenvolvimento mais a China ${ }^{2}$. Na ocasião se comemorou os cinquenta anos de criação do G77, momento em que recordaram a primeira Declaração Conjunta (firmada em 1964 em Genebra), que declara a unidade do Grupo para ampliar a cooperação na esfera internacional, se compromete em promover a igualdade na ordem econômica e social internacional, os interesses do mundo em desenvolvimento e as relações mutuamente benéficas para com o resto do mundo; também a primeira Reunião Ministerial (realizada em outubro de 1967 na Argélia), quando o G77 aprovou a Carta de Argel pela qual foram estabelecidos os princípios da unidade, complementariedade, cooperação e solidariedade dos países em desenvolvimento, e sua determinação em lograr o desenvolvimento econômico e social, quer individual ou coletivamente; assim como recordaram os êxitos da primeira Cúpula do Sul, do Grupo dos

Ver Anexo Países membros del G77. 
77 e a China (celebrada em Havana em abril de 2000), e da segunda Cúpula do Sul (celebrada em Doha em junho de 2005), justamente pela adoção de importantes Declarações e de planos de ação que vem guiando o Grupo e que constitui a base fundamental para a construção de uma nova ordem mundial e uma agenda própria dos países membros para a criação de um sistema mais justo, democrático e equitativo, que beneficie os povos do Sul.

Ao final do evento, a Declaração de Santa Cruz reafirmou as principais prioridades do G77, quais sejam: promover o crescimento econômico sustentável, inclusivo e equitativo; criar maiores oportunidades para todos; reduzir as desigualdades em todos os níveis, sobretudo no seio dos países membros; melhorar os níveis de vida básicos; fomentar o desenvolvimento social equitativo e inclusivo; promover uma ordenação integrada e sustentável dos recursos naturais e dos ecossistemas para que apoiem o desenvolvimento econômico, social e humano, facilitando ao mesmo tempo a conservação, a regeneração, o reestabelecimento e a resiliência do ecossistema frente aos novos e emergentes desafios; promover a cooperação Sul-Sul; e erigir o multilateralismo, garantindo que cada país tenha o direito soberano de decidir sobre suas próprias prioridades e estratégias de desenvolvimento, em especial no que se refere a igualdade entre os Estados, o respeito a independência, a soberania nacional, a integridade nacional e a não ingerência nos assuntos internos dos Estados, o que vai ao encontro dos princípios e propósitos da Carta das Nações Unidas e do direito internacional, a qual garantem respeitar plenamente.

O documento também recorda que o G77 estabeleceu uma secretaria permanente na sede das Nações Unidas (em Nova York) e formulou Capítulos em Genebra ${ }^{3}$, Nairóbi ${ }^{4}$, Paris ${ }^{5}$, Roma $^{6}$, Viena ${ }^{7}$ e Washington (Grupo dos 24$)^{8}$, e que já conta atualmente com 133 Estados membros ${ }^{9}-$ o que

\footnotetext{
Consultar http://www.g77.org/geneva/index.html

Consultar http://www.g77.org/nairobi/index.html

Consultar http://www.g77.org/paris/index.html

Consultar http://www.g77.org/rome/index.html

Consultar http://www.g77.org/vienna/index.html

Consultar http:/www.g24.org/index.html

São eles: Afeganistão, Argélia, Angola, Antígua e Barbuda, Argentina, Bahamas, Bahrain, Bangladesh, Barbados, Belize, Benin, Butão, Bolívia (Estado Plurinacional da), Bósnia e Herzegovina, Botswana, Brasil, Brunei Darussalam, Burkina Faso, Burundi, Camboja, Camarões, Cabo Verde, República Centro-Africano, Chade, Chile, China, Colômbia, Comores, Congo, Costa Rica, Côte d’Ivoire, Cuba, República Popular Democrática da Coreia, República Democrática do Congo, Djibouti, Dominica, República Dominicana, Equador, Egito, El Salvador, Guiné Equatorial, Eritreia, Etiópia, Fiji, Gabão, Gâmbia, Gana, Granada, Guatemala, Guiné, Guiné-Bissau, Guiana, Haiti, Honduras, Índia, Indonésia, Irã
} 
representa cerca de dois terços dos países que votam na Assembleia Geral das Nações Unidas, sendo a maior organização intergovernamental de países em desenvolvimento das Nações Unidas. E registrou que os pontos mais fortes do Grupo tem sido a sua unidade e solidariedade, a sua visão das relações multilaterais justas e equitativas, o compromisso dos Estados membros para com o bem estar dos povos do Sul e o seu empenho em promover uma cooperação mutuamente benéfica, que vem proporcionando os meios para que os países do Sul se articulem e promovam seus interesses econômicos e sociais, que de fato tem melhorado sua capacidade de negociação no sistema das Nações Unidas. Entre o legado e os grandes logros do G77 e China, destacaram: a defesa da promoção dos interesses dos países em desenvolvimento no último meio século, que pouco a pouco incrementou seu peso e influência em questões econômicas, sociais e ambientais; os progressos no desenvolvimento sustentável em níveis regional, nacional, subnacional e local; e os exemplos positivos de políticas que nos últimos anos vêm permitindo aos países reduzir a pobreza e ampliar a inclusão social.

Ainda nessa última Declaração, o G77 se compromete a consolidar essa base e a seguir construindo uma ordem mundial que seja justa, equitativa, estável e pacífica; dar continuidade na consolidação do desenvolvimento nacional e na união no plano internacional, nas áreas de estabelecimento de uma ordem internacional pacífica, justa na economia mundial e que ajude aos países em desenvolvimento a alcançar o crescimento econômico sustentável, o pleno emprego, a equidade social (para que contenha e reverta a situação de desigualdade entre os países membros); a fornecer bens e serviços básicos aos seus respectivos povos; respeitar e salvaguardar as identidades culturais, os conhecimentos e as tradições indígenas dos países membros; proteger o meio ambiente e a vida em harmonia com a natureza etc.

Mas junto com essas recordações, prioridades, registros de avanços e comprometimentos futuros, a Declaração também observou graves deficiên-

\footnotetext{
(República Islâmica do), Iraque, Jamaica, Jordânia, Quênia, Kiribati, Kuweit, República Democrática do Laos, Líbano, Lesoto, Libéria, Líbia, Madagáscar, Malavi, Malásia, Maldivas, Mali, Ilhas Marshall, Mauritânia, Maurício, Micronésia (Estados Federados da), Mongólia, Marrocos, Moçambique, Mianmar, Namíbia, Nauru, Nepal, Nicarágua, Níger, Nigéria, Oman, Paquistão, Panamá, Papua Nova Guiné, Paraguai, Peru, Filipinas, Catar, Ruanda, São Cristóvão e Nevis, Santa Lúcia, São Vicente e Granadinas, Samoa, São Tomé e Príncipe, Arábia Saudita, Senegal, Seychelles, Serra Leoa, Cingapura, Ilhas Salomão, Somália, África do Sul, Sri Lanka, Estado da Palestina, Sudão, Suriname, Suazilândia, República Árabe da Síria, Tadjiquistão, Tailândia, Timor-Leste, Togo, Tonga, Trinidad e Tobago, Tunísia, Turquemenistão, Uganda, Emirados Árabes Unidos, República Unida da Tanzânia, Uruguai, Vanuatu, Venezuela (República Bolivariana da), Vietnã, lémen, Zâmbia, Zimbábue.
} 
cias pelo não cumprimento dos objetivos do Grupo, assim como desafios e preocupações atuais. Em suma, o documento aponta que existem limitações em muitos países do Grupo no que refere a satisfação das necessidades relacionadas a água, alimentação, saúde, emprego, educação, habitação, infraestruturas física e de energia, e considera que a iminente crise ambiental apresenta consequências dramáticas no que diz respeito a escassez de água potável e perdas da biodiversidade. Considera que a desaceleração da economia mundial e seus consequentes efeitos, a falta de medidas sistêmicas e mecanismos adequados para o enfrentamento da atual crise financeira e econômica mundial, consistem em grandes desafios que o Grupo, individual e coletivamente, enfrentam. Assim, suas principais preocupações estão relacionadas com a atual crise da economia mundial - que segundo o Grupo evidenciou não apenas as debilidades e os desequilíbrios sistêmicos de longa data, mas também manifestou a insuficiência e o caráter antidemocrático da governança econômica mundial. Daí a necessidade de construção de novos acordos para estabelecer um sistema adequado de governança da economia mundial, com plena expressão, representação e participação dos países em desenvolvimento nos debates e na adoção de decisões. Suas preocupações também se relacionam com o aumento da concentração da riqueza e das rendas no mundo e sua distribuição assimétrica, capaz de criar grandes desigualdades nos países desenvolvidos e em desenvolvimento; com a influência das grandes empresas (sobretudo as sediadas nos países desenvolvidos) na economia mundial e os seus efeitos negativos no desenvolvimento econômico, social e ambiental de alguns países em desenvolvimento; e com o fato de alguns países em desenvolvimento (sobretudo os mais pobres e vulneráveis) ainda seguirem economicamente dependentes de estruturas da economia mundial e de países desenvolvidos e suas entidades econômicas, o que consequentemente limita a verdadeira independência política.

Muitas dessas preocupações e desafios não são novos, e certamente contribuem na compreensão da própria criação do G77. Mas os persistentes desequilíbrios da economia mundial e a desigualdade das estruturas e os resultados dos sistemas comercial, financeiro, monetário e tecnológico chegam a provocar em alguns aspectos efeitos ainda mais adversos para os países em desenvolvimento do que outrora. De tal forma que as razões para o estabelecimento do Grupo há 50 anos seguem reais e válidas, ainda mais 
válidas no presente do que no passado. Assim, não é sem propósito que o G77 e China voltem a se comprometer a fortalecer e ampliar esforços em todos os âmbitos em prol de melhores condições de vida de seus povos.

No passado, durante a Conferência de Bandung ${ }^{10}$, líderes asiáticos e africanos já haviam construído um programa mínimo comum, que consistiu em reconhecer que a batalha pelo direito histórico a independência não havia se concretizado, e que portanto deveriam levar a cabo um longo processo que começasse pela descolonização política da Ásia e da África e culminasse na libertação econômica, cultural e social de seus povos. Todos subscreviam os mesmos objetivos de independência política, modernização do Estado e industrialização da economia. A intervenção estatal era considerada absolutamente decisiva. Mas os líderes dessas nações estavam divididos quanto a alcançar o desenvolvimento na interdependência com a economia mundial ou abandonar o capitalismo como princípio para a reconstrução do campo socialista. (Amin, 2014).

Da Conferência de Bandung resultou uma Declaração destacando dez pontos sobre a promoção da paz e cooperação mundiais. São eles: 1) Respeito aos direitos humanos fundamentais, em conformidade com as finalidades e os princípios da Carta das Nações Unidas; 2) Respeito à soberania e à integridade territorial de todas as nações; 3) Reconhecimento da igualdade de todas as raças e de todas as nações, pequenas e grandes. 4) Não-intervenção e não-ingerência nas questões internas de outros países; 5) Respeito ao direito de cada nação se defender individualmente ou coletivamente, conforme a Carta das Nações Unidas; 6) Abstenção de uso de arranjos de defesa coletiva destinados a servir aos interesses particulares de alguma das grandes potências; abstenção de um país exercer pressões sobre outros; 7) Abstenção de atos ou ameaças de agressão ou de uso da força contra a integridade territorial ou a independência política de um país; 8) Tratamento de todas as disputas internacionais por meios pacíficos, tais como a negociação, a conciliação, a arbitragem ou a mediação de tribunais ou ainda ouros meios pacíficos de escolha das partes, conforme a Carta das

\footnotetext{
${ }^{10}$ A Conferência de Bandung (Indonésia) foi um encontro realizado entre os dias 18 e 24 de abril de 1955, e que contou com a participação de 29 países, sendo 23 da Ásia (Afeganistão, Birmânia, Camboja, Ceilão, República Popular da China, Filipinas, Índia, Indonésia, Japão, Laos, Nepal, Paquistão, República Democrática do Vietnã, Vietnã do Sul, Tailândia, Arábia Saudita, lêmen, Irã, Iraque, Jordânia, Líbano, Síria e Turquia) e 6 da África (Costa do Ouro (a atual Gana), Etiópia, Egito, Líbia, Libéria e Sudão).
} 
Nações Unidas; 9) Promoção dos interesses mútuos e da cooperação; 10) Respeito à justiça e às obrigações internacionais. ${ }^{11}$

A Conferência ficou conhecida pelo "não alinhamento" aos Estados Unidos e a União das Repúblicas Socialistas Soviéticas (URSS). Mas como nos lembra Eric Hobsbawn, "isso não quer dizer que os "não alinhados" fossem igualmente opostos aos dois lados da Guerra Fria" (2001, p.350). Não eram, uma vez que os inspiradores e defensores desse movimento eram ex-revolucionários coloniais radicais ${ }^{12}$, e todos esses juntamente com outros tantos dos ex-regimes coloniais, eram ou se diziam ser socialistas, e todos tinham alguma simpatia pela URSS ou pelo menos se mostravam dispostos a aceitar sua ajuda econômica e militar. Para Hobsbawn, o que havia de comum nesse movimento agrupado no que veio a ser conhecido como Terceiro Mundo (lembremos que desde a revolução cubana (1959) países latino-americanos inseriram-se no movimento), era o fato de todos serem pobres (comparados com o mundo desenvolvido), dependentes, terem governos que queriam se "desenvolver" - mas desde o mundo do após a Grande Depressão e da Segunda Guerra Mundial não mais acreditavam no mercado mundial capitalista ou na empresa privada espontânea para atingir tal fim. O "não alinhamento" é mais compreendido pelo temor que todos tinham de uma Terceira Guerra Mundial, e por isso queriam evitar juntar-se a qualquer um dos dois sistemas de aliança.

Sabemos que o movimento dos "não alinhados" ganhara e posteriormente perdera força, durante e antes mesmo do fim da Guerra Fria. E estamos convictos da necessidade do fortalecimento da solidariedade dos povos do Sul, de um novo Bandung. O que propomos neste artigo é apresentar tanto os motivos do surgimento e enfraquecimento do velho Bandung como debater as potencialidades que um novo Bandung apresenta aos povos do Sul e mais além. Para tanto, analisaremos o velho e o novo Bandung no contexto conjuntural do sistema mundial, sobretudo com base nos estudos de Giovanni Arrighi sobre a ascensão e transição da hegemonia norte-americana, bem como da ascensão chinesa diante do fracasso do "novo programa imperial" dos Estados Unidos.

Consultar: http://www.labpac.faed.udesc.br/oficina_Bandung.pdf

12 Hobsbawn lista Jawaharlal Nehru da Índia, Sukarno da Indonésia, o coronel Gamal Abdel Nasser do Egito e um dissidente comunista, o presidente Tito da lugoslávia, como os principais inspiradores e defensores de Bandung. 


\section{A HEGEMONIA MUNDIAL NORTE-AMERICANA E O VELHO BANDUNG}

Em O longo século XX: dinheiro, poder e as origens de nosso tempo, Giovanni Arrighi argumentou que ao final da Segunda Guerra Mundial sociedades mais uma vez encontraram-se num estado de desorganização irremediável, de "caos sistêmico", e que consequentemente também havia uma demanda generalizada de ordem. Os Estados Unidos tornaram-se mundialmente hegemônicos ao atenderem tal demanda. Conduziram inicialmente o sistema interestatal à restauração dos princípios, normas e regras do Sistema de Vestfália. Em seguida passaram a governar e a reformular o sistema de modo a erigir uma nova ordem mundial. A elite dirigente norte-americana mostrou possuir uma clara consciência dos problemas gerados pela luta pelo poder, e soube formular e oferecer uma solução para as demandas dos povos não ocidentais e dos não proprietários ocidentais. (Arrighi, 1997). Os contornos principais da nova ordem mundial centrada nos Estados Unidos já estavam configurados quando terminou a Segunda Guerra Mundial: "em Bretton Woods estabeleceram-se as bases de um novo sistema monetário; em Hiroshima e Nagasaki, novos recursos de violência demonstraram os alicerces militares da nova ordem; em San Francisco, novas regras e normas para legitimar a condução do Estado e da guerra foram explicitadas na Carta da ONU" (Arrighi \& Silver, 2001, p.90). Essa nova ordem mundial refletiu uma concentração de poder mundial sem precedentes.

Depois da Segunda Guerra Mundial, concedeu-se a todos os povos, "ocidentais" ou "não ocidentais", o direito à autodeterminação, ou seja, a se constituírem em comunidades nacionais e, uma vez constituídos, a serem aceitos como membros plenos do sistema interestatal. Nesse aspecto, a "descolonização" e a formação da Organização das Nações Unidas, cuja Assembleia Geral reuniu todas as nações em pé de igualdade, foram os correlatos mais significativos da hegemonia norte-americana. Ao mesmo tempo, a provisão da subsistência a todos os cidadãos tornou-se o objetivo fundamental a ser perseguido pelos membros do sistema interestatal. (...) a ideologia da hegemonia norte-americana elevou o bem-estar de todos os cidadãos (o "consumo de massa" em alto grau) acima dos direitos absolutos de propriedade e dos direitos absolutos de 
governo. (...) as instituições da hegemonia norte-americana restringiram consideravelmente os direitos e poderes de as nações soberanas organizarem relações com outros Estados e com seus próprios cidadãos como lhes aprouvesse. Os governos nacionais têm estado menos livres do que nunca para perseguir seus objetivos por meio da guerra, da expansão territorial e, em grau menor, mas ainda assim significativo, das violações dos direitos civis e humanos de seus cidadãos. (Arrighi, 1997, p.66-67).

Mas entre fins dos anos 1960 e início dos 1970, a hegemonia mundial norte-americana e o seu "regime de acumulação" viveu uma "crise sinalizadora". O desenvolvimento do desgaste da ordem monetária mundial se deu paralelamente ao da hegemonia mundial norte-americana nas esferas militar e ideológica. Já em 1973 a deterioração rápida da crise nestas três frentes fez o governo norte-americano recuar em todas elas. As estratégias então adotadas ao longo do restante dos anos 1970 passaram a se caracterizar por um desprezo básico de suas funções de governo mundial. O resultado foi uma desestabilização ainda maior do que havia restado da ordem mundial construída no após a Segunda Guerra, e um profundo declínio do poder e prestígio norte-americanos em fins dos anos 1970 e início dos anos 1980.

Militarmente, o exército norte-americano entrou em dificuldades crescentes no Vietnã. Ideologicamente, a cruzada anticomunista do governo estadunidense começou a perder legitimidade tanto no seu país como no exterior, sobretudo a partir da profunda crise cultural de 1968. As crises militar e de legitimidade do poderio mundial norte-americano foram por um lado a expressão do próprio sucesso que o rearmamento dos Estados Unidos e a ideologia da Guerra Fria obtiveram na transformação do "caos sistêmico" numa nova ordem mundial durante as décadas de 1930 e 1940, mas por outro expressaram a incapacidade de seu gigantesco aparato militar-industrial de lidar com os problemas suscitados pela descolonização do mundo. Em termos políticos, foi problemática a acomodação de dezenas de nações recém-emancipadas nas rígidas estruturas de poder da ordem mundial da Guerra Fria. A emergência no ano de 1955 do movimento de países "não-alinhados" em Bandung, exigindo uma Nova Ordem Econômica Internacional, mostrou que a plena soberania dos países do Terceiro Mundo constituía uma ameaça crescente ao poderio mundial norte-americano, pro- 
vavelmente até mais séria do que o próprio poderio soviético. Em termos econômicos, a recomposição da Europa Ocidental e do Japão à imagem dos Estados Unidos (concedendo também as suas classes trabalhadoras o elevado consumo de massa), combinada com a corrida armamentista americano-soviética, exerceu forte pressão sobre as reservas mundiais de insumos primários. Essa combinação resultou na ampliação da importância estratégica do Terceiro Mundo como reservatório de recursos naturais e humanos para atender as necessidades presentes e futuras das economias do Primeiro Mundo.

Os anos 1970 registraram uma súbita inversão nas relações de poder no sistema mundial, em prol dos países do Terceiro e Segundo Mundos e contra os do Primeiro Mundo. ${ }^{13}$ Os recursos naturais assim como a reserva de mão-de-obra abundante e barata daqueles países obtiveram grande demanda, e o fluxo de capital do Primeiro Mundo para os países do Terceiro e do Segundo Mundos apresentou uma grande expansão. Também contribuiu para esta inversão repentina a rápida industrialização dos países do Terceiro Mundo, que então passara a solapar a anterior concentração de atividades fabris nos países do Primeiro e do Segundo Mundos.

Ao se sentirem mais livres para acumular seus recursos naturais e humanos, e também mobilizá-los na busca de poder interno, regional ou mundial, as nações do Terceiro Mundo incitaram uma forte competição interestatal entre as nações do Primeiro Mundo pela garantia do abastecimento de tais recursos. A escalada igualmente repentina da competição intercapitalista, reduzindo os lucros reais do capital a baixos níveis, contribuiu para tornar esta inversão ainda mais profunda. Assim, a conjuntura econômica de boa parte dos anos 1970 favoreceu a muitos países que passaram a constituir o Terceiro Mundo. O resultado dessas competições para a burguesia do Ocidente em geral, e dos Estados Unidos em particular, fora uma experiência muito deprimente.

\footnotetext{
3 Segundo Arrighi, "O Terceiro Mundo foi um produto conjunto da revolta contra o Ocidente e da ordem mundial da Guerra Fria. Enquanto o mundo historicamente não-ocidental passou a se agrupar quase inteiramente no Terceiro Mundo, o Ocidente histórico se dividiu em três componentes distintos. O mais próspero (América do Norte, Europa Ocidental e Austrália), além do Japão, passou a constituir o Primeiro Mundo. Um dos menos próspero (União Soviética e Europa oriental) passou a constituir o Segundo Mundo; e o outro (América Latina) uniu-se ao mundo não-ocidental para constituir o Terceiro Mundo. Com o fim da Guerra Fria e o desaparecimento do Segundo Mundo, as expressões Primeiro e Terceiro Mundos tornaram-se anacrônicas e foram substituídas pelas expressões Norte e Sul globais, respectivamente" (2008, p.2I).
} 
Cabe ainda destacar ainda que a partir de 1968 começou a arrancada da atual fase de "expansão financeira" da economia mundial capitalista (centrada nos Estados Unidos), momento em que os fundos mantidos líquidos no mercado de eurodólares (centrado em Londres), experimentaram súbito e explosivo aumento. Mais tarde se tornaria impraticável sustentar a preservação do modo de emitir e regular o dinheiro mundial que então fora estabelecido em Bretton Woods. E entre a permanência da política monetária frouxa e a adesão mais rigorosa aos princípios e a prática da moeda forte, o governo norte-americano optou por forjar uma nova "aliança memorável" entre o poder do Estado e o capital, abandonando a frouxidão de suas políticas monetárias que haviam caracterizado toda a era da Guerra Fria. A contrarrevolução monetarista da era Ronald Reagan transformou a crise dos anos 1970 em uma nova belle époque do capitalismo norte-americano e mundial.

(...) o governo Reagan deu início a uma das mais espetaculares expansões do endividamento do Estado na história mundial. (...) esse aumento espetacular da dívida pública norte-americana associou-se a uma escalada da Guerra Fria com a União Soviética (...) e toda uma série de exibições de poderio militar contra uma seleção de países inamistosos do Terceiro Mundo (...). Como em todas as expansões financeiras anteriores, portanto, a mobilização da "vara de condão" que dota o dinheiro estéril do poder de procriação, sem a necessidade de ele se expor aos problemas e riscos inseparáveis da iniciativa produtiva - tal como Marx descreveu a "alienação do Estado" através das dívidas públicas - associou-se mais uma vez a uma escalada da luta interestatal pelo poder. E foi a competição pelo capital circulante, ocasionada por essa escalada mais recente na luta interestatal pelo poder, que, mais uma vez, parafraseando Weber, criou as melhores oportunidades para o capitalismo ocidental desfrutar de mais um "momento maravilhoso" de riqueza e poder sem precedentes. (Arrighi, 1997, p.328).

O "momento maravilhoso" para a burguesia do Ocidente assentavase num deslocamento da crise de um conjunto de relações para outro. Os governos do Terceiro Mundo foram os mais gravemente afetados pelos impactos causados pelo novo regime monetário. Chegara o momento em que os banqueiros do Primeiro Mundo deixaram de implorar aos países 
do Terceiro Mundo que tomassem emprestado seu capital hiperabundante. Agora eram os países do Terceiro e Segundo Mundos que competiam pelo escasso capital circulante, que imploravam aos governos e banqueiros do Primeiro Mundo que lhes concedessem o crédito necessário para se manterem à tona num mercado mundial cada vez mais integrado, competitivo e encolhido. Isso porque para financiar a "segunda Guerra Fria" e a compra de votos nas eleições internas, os Estados Unidos entraram agressivamente na competição pelo capital circulante nos mercados monetários mundiais, o que "esvaziou" rapidamente a oferta de recursos aos países do Terceiro e Segundo Mundos e provocou uma grande contração do poder aquisitivo mundial, como bem destaca a citação que se segue.

Os efeitos devastadores das políticas monetárias restritivas norte-americanas, das altas taxas de juros e da desregulamentação logo colocaram os países do Terceiro Mundo de joelhos. $\mathrm{O}$ endurecimento das políticas monetárias norte-americanas reduziu drasticamente a demanda de suprimentos oriundos do Terceiro Mundo. Como resultado, entre 1980 e 1988, os preços reais das exportações de produtos do Sul declinaram uns $40 \%$ (...). Os pagamentos latino-americanos de juros da dívida, por exemplo, subiram de menos de 1/3 de suas exportações, em 1977, para quase $2 / 3$ em 1982 . O estado generalizado de falência de facto, daí decorrente, selou a inversão da sorte dos países do Terceiro Mundo nos mercados financeiros mundiais. (Arrighi, 1997, p.334-335).

Os países que se apressaram em se vincular aos circuitos globais do capital nos anos 1970, assumindo pesados compromissos financeiros, logo se viram em situações de desespero, a começar pela Polônia em 1980, o México em 1982, e também o Brasil em 1986, além de tantas outras nações. Escrevendo sobre "as décadas de crise" (1973-1992), e no que diz respeito ao chamado Terceiro Mundo, Hobsbawn afirmou que para esta vasta área

Só uma generalização era bastante segura: desde 1970, quase todos os países dessa região haviam mergulhado profundamente em dívida. (...) Os países mais pesadamente endividados, relativamente, não surpreendentemente se encontravam na África (...) os países que tinham de suportar o custo mais pesado do serviço dessas imensas dívidas, quer dizer, onde 
elas equivaliam a um quarto ou mais das exportações do país, achavam-se ainda mais regularmente espalhados. Na verdade, entre as regiões do mundo, a África subsaariana estava um tanto abaixo dessa cifra, em melhores condições sob esse aspecto do que o sul da Ásia, a América Latina e o Caribe e o Oriente Médio. (...) Enquanto suas dívidas cresciam, os bens reais ou potenciais dos Estados pobres não o faziam. A economia mundial capitalista, que julga exclusivamente por lucro ou lucro potencial, decidiu claramente cancelar, uma grande parte do Terceiro Mundo nas Décadas de Crise. (Hobsbawn, 2001, p.411-412).

O Terceiro Mundo em geral sofreu com o severo arrocho em seus orçamentos estatais a ponto de desmantelar antigos instrumentos de luta contra o desemprego, abandonar projetos de desenvolvimento em favor de ajustes estruturais e dos programas de austeridade impostos pelo Fundo Monetário Internacional (FMI), com o propósito de torná-los solventes nos mercados financeiros mundiais. O resultado foi um mal-estar social, a ampliação da pobreza, a polarização crescente da riqueza dentro e entre as nações, enquanto também se aprofundava o fosso Norte-Sul ${ }^{14}$ e as subsequentes crises de legitimação das elites mundiais.

Na década de 1980 e início da de 1990, o mundo capitalista viu-se novamente às voltas com problemas da época do entreguerras que a Era de Ouro parecia ter eliminado: desemprego em massa, depressões cíclicas severas, contraposição cada vez mais espetacular de mendigos sem teto a luxo abundante, em meio a renda limitadas de Estado e despesas ilimitadas de Estado. (Hobsbawn, 2001, p.19-20).

Não se deve atribuir a mais recente "expansão financeira" exclusividade na explicação do ressurgimento desses velhos problemas, mas o certo é que seus efeitos não foram desprezíveis. A análise dos "ciclos sistêmicos de acumulação" 15 sugere que as etapas de "expansão material" são propícias à

\footnotetext{
14 Para Arrighi \& Silver, que examinaram a classificação dos países de acordo com o PIB per capita, "as décadas de 1980 e 1990 viram a vasta maioria do Sul (...) retroceder, estagnar ou crescer mais devagar que o Norte" (200 I, p.221).

15 Um completo "ciclo sistêmico de acumulação" compreende duas épocas distintas. Há uma primeira fase de "expansão material" - momento em que "o capital monetário "coloca em movimento" uma massa crescente de produtos (que
} 
prosperidade nacional mais ampla, aos avanços da indústria, do transporte e do comércio, a expansão dos empregos, das rendas e das riquezas. Já no curso das etapas de "expansão financeira" há concentração de capital em escala mundial, no duplo sentido dele direcionar-se para um centro comum e ganhar força, densidade ou intensidade. Apenas uma pequena parcela elitizada de suas populações nacionais pode dividir os lucros da bolsa, dos bancos mercantis e das corretoras de valores. As finanças não podem alimentar uma grande classe média e muito menos as camadas sociais mais baixas.

$\mathrm{O}$ atual processo de financeirização parece ter percorrido um caminho conhecido: a financeirização, a polarização da riqueza e o abandono do pacto social que ligava os sócios minoritários ao bloco hegemônico criando crises generalizadas de legitimação das elites mundiais. Como toda belle époque à belle époque do regime norte-americano mais aprofundou do que solucionou as contradições subjacentes da "crise sinalizadora" anterior. Mas essa também estava fadada a ser um fenômeno temporário, independentemente do que façam os governos das hegemonias em decadência, pois as "expansões financeiras" impactam de maneira contraditória sobre a estabilidade do sistema.

A curto prazo - entenda-se que, nesse contexto, o curto prazo significa décadas, em vez de anos -, as expansões financeiras tendem a estabilizar a ordem existente porque permitem que os grupos hegemônicos dominantes repassem para os grupos nacional e internacionalmente subordinados o fardo da intensificação da concorrência que ameaça sua hegemonia. (...) com o tempo, as expansões financeiras tendem a desestabilizar a ordem em vigor por meio de processos que são tanto sociais e políticos quanto econômicos. Em termos econômicos, elas desviam sistematicamente o poder de compra do investimento em commodities (até mesmo a força de trabalho), criador de demanda, para a acumulação e a especulação, exacerbando assim os problemas de realização dos lucros. Em termos

inclui a força de trabalho e dádivas da natureza, tudo transformado em mercadoria)" - seguida por uma segunda fase de "expansão financeira - momento em que uma massa crescente de capital monetário "liberta-se" de sua forma mercadoria, e a acumulação prossegue através de acordos financeiros". A investigação de Arrighi identificou quatro "ciclos sistêmicos de acumulação": "um ciclo genovês, do século XV ao início do século XVII; um ciclo holandês, do fim do século XVI até decorrida a maior parte do século XVIII; um ciclo britânico, da segunda metade do século XVIII até o início do século XX; e um ciclo norte-americano, iniciado no fim do século XIX e que prossegue na atual fase de expansão financeira". (1997, p.06). 
políticos, tendem a se associar ao surgimento de novas configurações de poder, que minam a capacidade do Estado hegemônico dominante de se aproveitar da intensificação da concorrência em todo o sistema. E, em termos sociais, trazem consigo a redistribuição maciça de remuneração e de deslocamentos sociais, que tendem a provocar movimentos de resistência e rebelião nos grupos e nos estratos subordinados, cujos modos de vida tradicionais sucumbem ao ataque. (Arrighi, 2008, p.171-172).

Arrighi responsabilizou a contrarrevolução monetarista pela destruição das bases do velho Bandung, e viu na desestabilização da ordem proporcionada pela hegemonia mundial norte-americana e sua subsequente "crise terminal", simultânea a ascensão chinesa, possibilidades e potencialidades da emergência de um novo Bandung. É para esse novo tempo que agora voltaremos as atenções.

\section{A ASCENSÃO CHINESA E AS POTENCIALIDADES DE UM NOVO BANDUNG}

No já citado $O$ longo século $X X$, Arrighi apontou três possíveis desfechos da atual crise do "regime de acumulação" norte-americano:

Os Estados Unidos e seus aliados europeus poderiam usar sua superioridade militar para impor um "pagamento de proteção" aos centros capitalistas emergentes da Ásia oriental. Se a tentativa fosse bem-sucedida, talvez viesse a existir o primeiro império verdadeiramente global da história do mundo. Se essa tentativa não se realizasse ou não fosse bem-sucedida, com o tempo a Ásia oriental poderia se tornar o centro de uma sociedade de mercado mundial do tipo vislumbrado por Adam Smith. Mas é possível também que essa bifurcação resultasse em um caos mundial interminável. (Arrighi, [1994] 2008, p.22-23).

Passados duas décadas dessas previsões, essas possibilidades ainda estão em aberto, mas a opção do meio ganhou força. E em outro trabalho, Adam Smith em Pequim: origens e fundamentos do século XXI, dirigiu sua atenção para a formulação e o abandono do Projeto neoconservador para o Novo Sé- 
culo Norte-Americano, e o surgimento da China como líder do renascimento da Ásia oriental. Dois fatos que acredita estar, mais do que tudo, configurando a política, a economia e a sociedade mundiais. Um de seus objetivos nessa sua última obra foi interpretar a atual transferência do epicentro da economia política global da América do Norte para a Ásia oriental a partir da teoria de desenvolvimento econômico de Adam Smith ${ }^{16}$. Seu embasamento teórico consistiu em examinar primeiramente a descoberta feita por André Gunder Frank da importância da teoria do desenvolvimento econômico de Smith para a compreensão do que Kenneth Pomeranz chamou de "Grande Divergência" "17. Depois reconstruiu a teoria de Smith e comparou-a com as teorias de desenvolvimento econômico de Karl Marx e Joseph Schumpeter. Deste exercício "brotou" uma "perspectiva smithiana ampliada", da qual se vale tanto para acompanhar a atual turbulência global quanto para examinar a ascensão econômica da Ásia oriental e da China em particular.

Um importante resultado desse trabalho aparece na defesa da sua tese geral, ou seja, a de que

o fracasso do Projeto para o Novo Século Norte-Americano e o sucesso do desenvolvimento econômico chinês, tomados em conjunto, tornaram mais provável do que nunca, nos quase dois séculos e meio desde a publicação de $A$ riqueza das nações, a concretização da idéia de Smith de uma sociedade mundial de mercado baseada em uma maior igualdade entre as nações. (Arrighi, 2008, p.24).

O Projeto para o Novo Século Norte-Americano foi traduzido por Arrighi como o "novo programa imperial" neoconservador do governo de George W. Bush, desatado logo o após os ataques ao World Trade Center e ao Pentágono em 11 de setembro de 2001. A reação do governo Bush a esses atentados por meio da invasão ao Iraque no ano de 2003 precipitou a "crise terminal" da hegemonia norte-americana, transformando-a em pura dominação. Em suma, tal projeto consistiu basicamente em "dar vida ao pri-

\footnotetext{
${ }^{16}$ O outro objetivo foi apresentar uma interpretação de "A riqueza das Nações" à luz desta transferência do epicentro da economia política global.

17 A "Grande Divergência" de Pomeranz remete a intensa separação entre os destinos políticos e econômico da Europa e da Ásia oriental, que no passado apresentavam padrões de vida semelhantes. Ver POMERANZ, Kenneth. The Great Divergence: Europe, China and making of the modern World economy. Princeton : Princeton University Press, 2000.
} 
meiro império verdadeiramente global da história do mundo" (2008, p.23), mas fracassou duplamente pois "não conseguiu pôr fim à chamada síndrome do Vietnã, tampouco lançar as bases de um novo século norte-americano" (idem, p.188). Todos sabemos que os Estados Unidos continuam a ser a potência militar predominante no mundo, e é certo que sua influência foi e é também considerável no novo "equilíbrio do terror". Mas a capacidade de angariar fundos para levar a cabo suas políticas militares parecem ser atualmente menores do que no passado. ${ }^{18} \mathrm{E}$ mais, o impacto da guerra no Iraque comprometeu não só a credibilidade do poderio militar dos Estados Unidos, também reduziu (ainda mais) a centralidade do país e da moeda na economia política global, ao passo que não intencionalmente fortaleceu a promoção da China como alternativa a liderança norte-americana na Ásia oriental e mais além.

Há uma perda tanto relativa quanto absoluta na capacidade de os Estados Unidos manter a centralidade no interior da economia política global. A China vem substituindo-o (e cada vez mais) como principal motor da expansão comercial e econômica não só na região da Ásia oriental como em outras regiões do mundo. O Consenso de Pequim, na visão de Joshua Cooper Ramo 19 , oferece a "localização" e o "multilateralismo" para o Sul do globo: "localização" representa "o reconhecimento da importância de ajustar o desenvolvimento às necessidades locais, que diferem obrigatoriamente de um lugar para outro, em forte contraste com a receita do "tamanho único" do Consenso de Washington"; e o "multilateralismo" e "o reconhecimento da importância da cooperação entre os Estados para construir uma nova ordem global com base na interdependência econômica, mas que respeite as diferenças políticas e culturais, em forte contraste com o unilateralismo das políticas norte-americanas" (Arrighi, 2008, p.383).

Os resultados para os países que adotaram as contrarreformas neoliberalizantes emanadas do Consenso de Washington foram em geral descritos como decepcionantes por um amplo conjunto de estudiosos. Gérard Duménil e Dominique Lévy, por exemplo, sintetizaram tais resultados em quatro pontos centrais:

${ }_{18}$ Arrighi defende a tese de que "a superioridade da força ocidental atingiu seu limite e apresenta forte tendência a implodir" (2008, p.25).

19 Ver RAMO, Joshua Cooper. The Beijing Consensus: Notes on the New Physics of Chinise Power. London, Foreign Affairs Policy Centre, 2004. 
(1) o neoliberalismo criou formidáveis fluxos de rendas em benefícios das camadas mais ricas; (2) estabeleceu-se um poderoso sistema de drenagem de rendas no plano mundial, alimentando as rendas dessas camadas, que (3) se engajaram num consumo maluco e (4) o investimento, reduzido no neoliberalismo, manteve nível superior ao ditado pela poupança nacional graças ao aporte da poupança internacional que financiou a despesa nos Estados Unidos. (Duménil e Lévy, 2005, p.98-99).

O caso da América Latina ilustra bem a decepção com as contrarreformas neoliberais: baixo crescimento econômico, exclusão social, pobreza, concentração de renda, precarização das relações de trabalho, aumento do desemprego, expansão da violência, instabilidade política etc. Contudo, não é de surpreender a crescente agitação da resistência mundial contra os efeitos da neoliberalização do capitalismo, sobretudo nesta região que se tornou símbolo das convergências dos movimentos sociais. Organizações camponesas, indígenas, movimentos de mulheres, coletivos militantes, organizações não governamentais, organizações sociais e juvenis veem formando nos últimos anos uma verdadeira "aliança global”. Do I Encontro Intercontinental pela Humanidade e contra o Neoliberalismo, em Chiapas no México (1996), passando por Seattle (1999) ao décimo quarto Fórum Social Mundial (2010), um heterogêneo e amplo movimento vem se organizando na forma do que José Seoane e Emílio Taddei (2001) chamaram provisoriamente de "movimento antimundialização neoliberal".

A adoção do receituário do Consenso de Washington (abertura econômica, privatizações, desregulamentação e flexibilização) e seus resultados de um lado, e a agitação dos movimentos sociais de outro, fez com a América Latina ampliasse nos últimos anos (desde 1998) espaços eleitorais à esquerda: Hugo Chavés e Nicolás Maduro na Venezuela, os Kirchner na Argentina, Luiz Inácio Lula da Silva e Dilma Rousseff no Brasil, Michelle Bachelet no Chile, Evo Morales na Bolívia, Rafael Correa no Equador, Tabaré Vazquez e José Mujica no Uruguai, Fernando Lugo no Paraguai (deposto por um golpe sem sangue) etc. Mas antes mesmo da esquerda e centro-esquerda ocupar o poder em diversos países na América Latina, já era evidente que o "triunfalismo neoliberal" havia acabado, como bem assinalou Hobsbawn. 
(...) o triunfalismo neoliberal não sobreviveu aos reveses econômicos de início da década de 1990, nem talvez à inesperada descoberta de que a economia mais dinâmica e de crescimento mais rápido do globo, após a queda do comunismo soviético, era a China comunista. (Hobsbawn, 2001, p.402).

Os promotores institucionais do Consenso de Washington - o Banco Mundial, o FMI, os Tesouros dos Estados Unidos e do Reino Unido, assim como a mídia formadora de opinião, a exemplo do Financial Times e The Economist - atribuíram o crescimento econômico da China (desde 1980) e a consequente redução da pobreza no mundo ao fato dos chineses terem adotado as políticas por eles recomendadas. Arrighi desmente a afirmativa com base "na longa série de desastres econômicos que a adoção real da receita provocou na África subsaariana, na América Latina e na antiga União Soviética". E argumenta que "a desregulamentação e a privatização [na China] foram bem mais seletivas e avançaram em ritmo bem mais lento do que nos países que seguiram a receita neoliberal" (2008, p.361-362). A sua avaliação é a de que as reformas de Deng Xiaoping não seguiram a receita neoliberal, e a tese de que a China adotou tal receituário não passa de um mito, proclamado tanto por intelectuais de esquerda como pelos promotores institucionais do Consenso de Washington. E defende que "a fé utópica que o credo neoliberal dedica aos benefícios das terapias de choque, aos governos minimalistas e aos mercados auto-regulados era (...) estranha aos reformadores chineses" (idem p.363), e que o retorno da China a economia de mercado seguiu num relativo gradualismo onde o papel do governo na promoção do desenvolvimento fora inclusive ampliado ${ }^{20}$.

Arif Dirlik acredita que as características do Consenso de Pequim podem levar o mundo em duas direções radicalmente distintas: a formação de um novo Bandung ou a cooptação dos Estados do Sul do globo em alianças Norte-Sul para conter a subversão, liderada pela China, da hierarquia global da riqueza. Arrighi destaca três tipos diferentes de aliança Norte-Sul como as alternativas mais "realistas" para a estratégia neoconservadora fracassada

20 Tal ampliação pôde ser percebida nas "enormes quantias de investimento no desenvolvimento de novos setores, na criação de novas Zonas de Processamento para Exportação (ZPEs), na expansão e na modernização da educação superior e em grandes projetos de infra-estrutura, num nível sem precedentes em nenhum país de renda per capita comparável" (Arrighi, 2008, p.362). 
dos Estados Unidos em reverter a atual transferência de poder para o Sul global, sobretudo para a China.

\begin{abstract}
(...) implantadas com coerência ou não, todas as três estratégias têm potencial para fazer descarrilar a formação de uma nova aliança do Sul que seja capaz de contrabalançar o domínio do Norte. O descarrilamento mais desastroso seria aquele implícito na estratégia do tertius gardens de Pinkerton, que defende a reprise da primeira metade do século $\mathrm{XX}$, quando os Estados Unidos se tornaram ricos e poderosos financiando e suprindo os Estados em guerra entre si, com a diferença de que agora os Estados em guerra seriam asiáticos, e não europeus. O descarrilamento menos desastroso seria aquele implícito na estratégia de Kissinger, que vislumbra a cooptação da China numa ordem mundial reformada e centrada nos Estados Unidos, porque, se bem sucedida, preservaria o domínio do Norte, mas pelo menos não lançaria a Ásia e o Sul do globo no caos e na guerra que o sucesso da estratégia do tertius gardens acarretaria. Para o Sul, o custo e os riscos da estratégia Kaplan - cercar a China com uma aliança militar encabeçada pelos Estados Unidos, numa reprise da Guerra Fria, mas dessa vez centrada na Ásia em vez da Europa - ficariam numa posição intermediária. Isso provocaria divisões profundas entre os países da Ásia e do hemisfério Sul, e traria de volta o risco do holocausto nuclear que a antiga Guerra Fria conseguiu evitar, mas obrigaria os Estados Unidos a tratar com certo respeito e a fazer concessões aos seus aliados do Sul, além de terem cautela ao provocar guerras em que se envolvessem diretamente. (Arrighi, 2008, p.384).
\end{abstract}

O alerta que faz é para não subestimarmos a tentação da China e de outros países do Sul de se contentar em ser cooptados numa ordem mundial dominada pelos Estados Unidos ou pelo Norte. Mas tampouco superestimarmos o poder dos Estados Unidos (mesmo em conluio com a Europa) de ser bem-sucedido na implantação de qualquer uma dessas estratégias, uma vez que a contrarrevolução monetarista do início da década de 1980 saiu pela culatra e criou condições mais favoráveis do que nunca para a emergência de um novo Bandung (2008, p.384 e 388), uma nova versão da aliança do Terceiro Mundo vigente nas décadas de 1950 e 1960. 
Assim como o velho Bandung, essa nova versão também visaria contrabalançar a subordinação econômica e política, mas seria mais adequado a uma época de integração econômica global sem precedentes. E quanto às potencialidades do novo em relação ao velho Bandung, Arrighi afirma que

um novo Bandung pode fazer o que o velho não conseguiu: mobilizar e usar o mercado global como instrumento de equalização das relações de poder entre Norte e Sul. As bases do antigo Bandung eram estritamente político-ideológicas e, sendo assim, foi fácil destruí-las com a contra-revolução monetarista. As bases do Bandung que pode estar surgindo agora, por outro lado, são basicamente econômicas e, como tais, mais sólidas. (Arrighi, 2008, p.388).

Às crescentes relações comerciais e econômicas travadas entre a China e diversos outros países das regiões da Ásia, África e América Latina não corroboram a maior solidez das bases de um novo Bandung? Arrighi aponta o fato da crise financeira asiática de 1997/1998 ter marcado o início de uma enorme bifurcação entre o déficit do Norte e o superávit do restante do mundo nas transações correntes de seus respectivos balanços de pagamentos, então na faixa de $2,5 \%$ do PIB mundial em $2006^{21}$. Tal bifurcação é explicada pelo fato de que há cada vez menos mercadorias e serviços que o Norte, sobretudo os Estados Unidos, possa produzir a preços mais competitivos que o resto do mundo. Parte significativa do superávit do resto do mundo ainda flui para o entreposto financeiro norte-americano, seja para financiar o gigantesco déficit dos Estados Unidos seja para ser reinvestido no mundo inteiro. Mas uma parte crescente desse superávit tem buscado o aumento de reservas cambais e/ou flui para outros destinos do Sul, o que contribui para reduzir o domínio do FMI e de outras instituições financeiras controladas pelo Norte, e consequentemente a fragilidade do Sul.

Apesar da compra maciça de títulos do Tesouro norte-americano, a China desempenhou o papel principal tanto no redirecionamento do superávit do Sul para destinos no próprio Sul quanto na apresentação aos países vizinhos e distantes do hemisfério Sul alternativas atraentes para o comércio, os

${ }^{21}$ Fonte: Banco de Dados de Resultados Econômicos do FMI, setembro de 2006. 
investimentos e o auxílio dos países e das instituições financeiras do Norte. (...) Para suplementar e complementar as iniciativas chinesas, os países ricos em petróleo também estão redirecionando seu superávit para o Sul. (...) Tem sido igualmente importante e, em termos potenciais, mais prejudicial para o domínio financeiro do Norte o interesse recentemente demonstrado pela Arábia Saudita e por outros países da Ásia ocidental em retirar dos Estados Unidos e da Europa pelo menos uma parte de seus superávits e redirecioná-los para o sul e para o leste da Ásia. (Arrighi, 2008, p.386-387).

Por fim, Arrighi levantou duas questões fundamentais para monitorarmos os processos de emancipação dos países do Sul e mesmo do mundo em geral diante da devastação social e ecológica provada pelo desenvolvimento capitalista "antinatural" (Smith) ocidental. A primeira é saber se os países asiáticos e do hemisfério sul destinarão o superávit de seus balanços de pagamentos como instrumento de emancipação do Sul ou se o usarão preponderantemente à disposição dos órgãos controlados pelos Estados Unidos para ser transformados em instrumento de dominação do Norte. E a segunda é saber se os grupos dominados do hemisfério Sul em geral, e da China e da Índia em particular, serão ou não capazes de abrir um caminho distinto de desenvolvimento, mais "natural” (Smith), igualitário e ecológico.

\section{CONSIDERAÇÕES}

O velho Bandung nasceu em meados do século XX a partir do reconhecimento de que a batalha pelo direito histórico a independência de nações do Sul não havia até então se concretizado, e que urgia levar a cabo um longo processo que começasse pela descolonização política da Ásia e da África e culminasse na libertação econômica, cultural e social de seus povos. Mas as bases político-ideológicas desse movimento dos "não alinhados" foram destroçadas pela contrarrevolução monetarista da era Reagan, numa tentativa momentaneamente bem sucedida de transformar a crise dos anos $1970 \mathrm{em}$ uma nova belle époque do capitalismo norte-americano e mundial. Como vimos, as consequências para o Terceiro Mundo em geral foram desastrosas, produzindo grande mal-estar social, ampliação da pobreza, polarização crescente da riqueza dentro e entre as nações, bem como aprofundando o 
fosso entre o Norte e Sul, onde este padeceu com o severo arrocho em seus orçamentos estatais, a ponto mesmo de desmantelar antigos instrumentos de luta contra o desemprego, abandonando projetos de desenvolvimento em favor de ajustes estruturais e programas de austeridade impostos pelo FMI.

Mas como toda belle époque também a do "regime de acumulação" norte-americano mais aprofundou do que solucionou as contradições subjacentes da "crise sinalizadora" da hegemonia estadunidense, dado que as "expansões financeiras" impactam de maneira contraditória sobre a estabilidade do sistema, independentemente do que façam os governos das hegemonias em decadência. Os promotores institucionais do Consenso de Washington bem que tentaram subverter as subsequentes crises de legitimidade das elites mundiais, mas os resultados para os países que adotaram as contrarreformas neoliberalizantes emanadas desse Consenso foram desastrosas. E a trágica reação do governo Bush aos atentados de 11 de setembro só precipitou a "crise terminal" da hegemonia norte-americana. Giovanni Arrighi propôs a tese de que o "novo programa imperial" neoconservador desse governo fracassou duplamente, uma vez que não conseguiu pôr fim à chamada síndrome do Vietnã e tampouco conseguiu lançar as bases de um novo século norte-americano. A contrapartida foi não só reduzir a centralidade dos Estados Unidos e de sua moeda na economia política global, mas intencionalmente também fortaleceu a China como alternativa à liderança norte-americana na Ásia oriental e em outras regiões do Sul, como bem demonstra a proposição do Consenso de Pequim.

Arrighi destacou três tipos diferentes de aliança Norte-Sul (tertius gardens de Pinkerton; a estratégia de Kissinger; e a estratégia Kaplan) que têm potencial para fazer descarrilar a formação de uma nova aliança do Sul que seja capaz de contrabalançar o domínio do Norte. Todas estão em aberto. Mas também alertou que não se pode descartar a formação de um novo Bandung que tem o potencial de usar o mercado global como instrumento de equalização das relações de poder entre Norte e Sul, algo que o velho Bandung não fez. Se o fizer assentará bases não só político-ideológicas como econômicas. Demonstrações das identidades política-ideológicas foram dadas nas Cúpulas do Sul em Havana (2000), em Doha (2005) e mais recentemente na Bolívia (2014), momento em que o G77 e China voltou a se reunir e reafirmar as prioridades do Grupo, os registros de avanços e comprometimentos futuros, bem como apontar as graves deficiências no não 
cumprimento dos objetivos do Grupo, assim como desafios e preocupações atuais. No âmbito econômico é preciso melhorar identificar as crescentes relações comerciais e econômicas travadas entre o Sul global, especialmente entre a China e diversos outros países das regiões da Ásia, África e América Latina, assim como acompanhar o destino que está tomando o superávit do balanço de pagamentos do resto do mundo em relação ao déficit do Norte. E não menos importante, precisamos monitorar o caminho de desenvolvimento que o Sul em geral (e os BRICS em particular) vem tomando, pois só assim veremos se somos ou não capazes de abrir um caminho distinto daquele que nos devastou social e ecologicamente.

\section{THE OLD AND THE NEW BANDUNG IN THE CONTEXT OF THE WHOLE WORLD SYSTEM}

\section{Abstract}

We present the recent Santa Cruz Joint Declaration of the Seventy-Seven Developing Countries (G77) and China, which took place in Santa Cruz de la Sierra (Bolivia), highlighting memories, priorities, records of progress and future commitments, but also serious deficiencies in meeting the objectives of the Group as well as its current challenges and concerns. We know that many of these challenges and concerns are not new, since they were already there at the Bandung Conference and before. Our proposal here is to highlight the reasons for the emergence and the weakening of the old Bandung and discuss the potential that the new Bandung presents to the people of the South. In order to do that, we will analyze the old and the new Bandung in the context of the whole world system, especially based on the study of Giovanni Arrighi about the rise and transition of the American hegemony and about China's rise, given the failure of the "new imperial program" of the United States.

Keywords: US world hegemony; old and new Bandung; China's rise; G77; China.

J.E.L. Classification: F50 


\section{REFERÊNCIAS}

ARRIGHI, Giovanni. O Longo Século XX: dinheiro, poder e as origens de nosso tempo. Rio de Janeiro : Contraponto, 1997.

- Adam Smith em Pequim: origens e fundamentos do século XXI. São Paulo : Boitempo, 2008.

ARRIGHI, Giovanni \& SILVER, Beverly J. (Orgs). Caos e Governabilidade no Moderno Sistema Mundial. Rio de Janeiro : Contraponto ; Editora da UFRJ, 2001.

DUMÉNIL, Gérard \& LÉVY, Dominique. O neoliberalismo sob a hegemonia norte-americano. In: CHESNAIS, François. (org.). A finança mundializada: raízes sociais e políticas, configuração, consequências. São Paulo : Boitempo, 2005.

HOBSBAWN, Eric. A era dos extremos: o breve século XX (1914-1991). São Paulo : Companhia das Letras, 2001.

SEOANE, José \& TADDEI, Emílio. Resistências mundiais: de Seattle a Porto Alegre. Petrópolis : Vozes, 2001.

\section{Sites consultados}

AMIN, Samir. A Conferência de Bandung, 50 anos depois. Entrevista concedida ao Avante! Disponível em: <http://www.avante.pt/pt/1642/internacional/9632/>, acessado em 25 de julho de 2014.

CONFERÊNCIA DE BANDUNG. Países partícipes. Disponível em: $<$ http://pt.wikipedia.org/wiki/Ficheiro:Asian-African_Conference_Participants.svg>, acessado em 26 de julho de 2014.

CUMBRE DE JEFAS Y JEFES DE ESTADO Y DE GOBIERNO DEL GRUPO DE LOS 77. Declaración de Santa Cruz. Disponível em: $<$ http:// www.g77bolivia.com/es/declaracion-de-santa-cruz>, acessado em 23 de julho de 2014. 
DIRLIK, Arif. Beijing Consensus: Beijing "Gongshi”: Who Recognizes Whom and to What End? Globalization and Autonomy Online Compendium. Disponivel em <http://www.globalautonomy.ca/globall/position.jps?index=PP_Dirlik_BeijingConsensus.xml>, acessado em 06 de agosto de 2014 .

GONÇALVES, Janice. Conferência de Bandung: desafio à ordem bipolar? Disponível em: < http://www.labpac.faed.udesc.br/oficina_Bandung.pdf>, acessado em 1 de agosto de 2014.

INTERGOVERNMENTAL GROUP OF TWENTY FOUR. Disponível em: <http:/www.g24.org/index.html>, acessado em 24 de julho de 2014.

NACIONES UNIDAS EN BOLIVIA. Países membros del G77. Disponível em: <http://www.nu.org.bo/snu/paises-miembros-del-g77>, acessado em 25 de julho de 2014 .

THE GROUP OF 77 AT THE UNITED NATIONS. Disponível em: < http:// www.g77.org/index.html>, acessado em 23 e 24 de julho de 2014.

\section{ANEXO}

Países partícipes da Conferência de Bandung

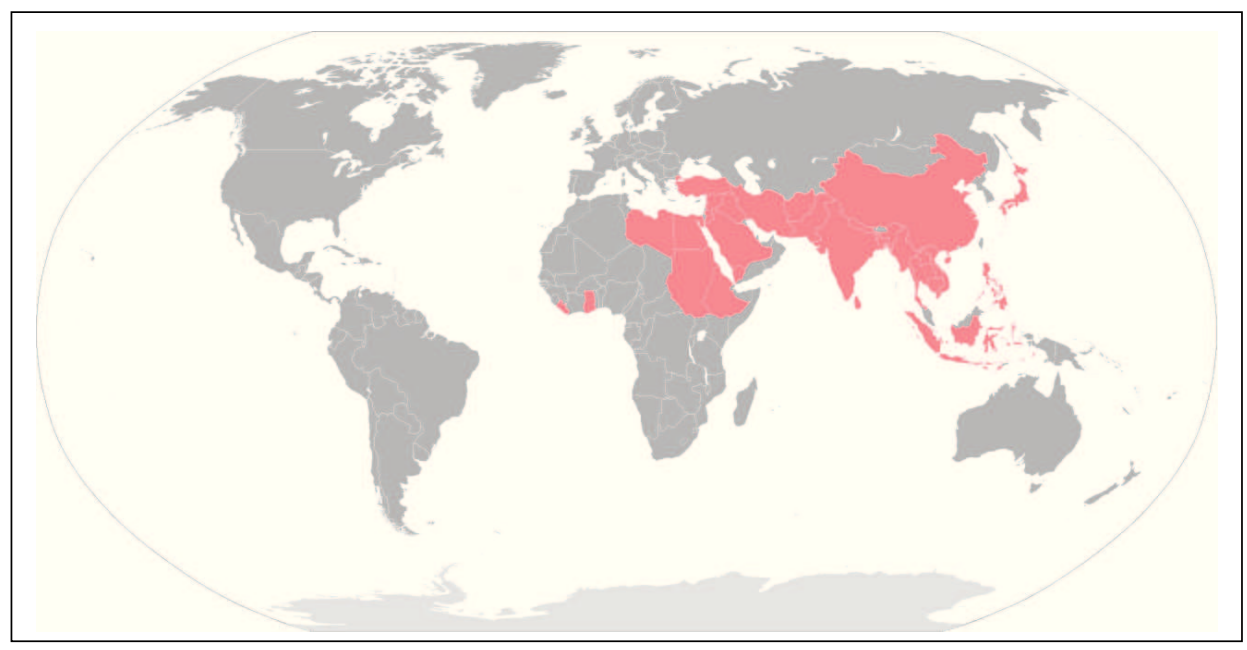

Fonte: http://pt.wikipedia.org/wiki/Ficheiro:Asian-African_Conference_Participants.svg 


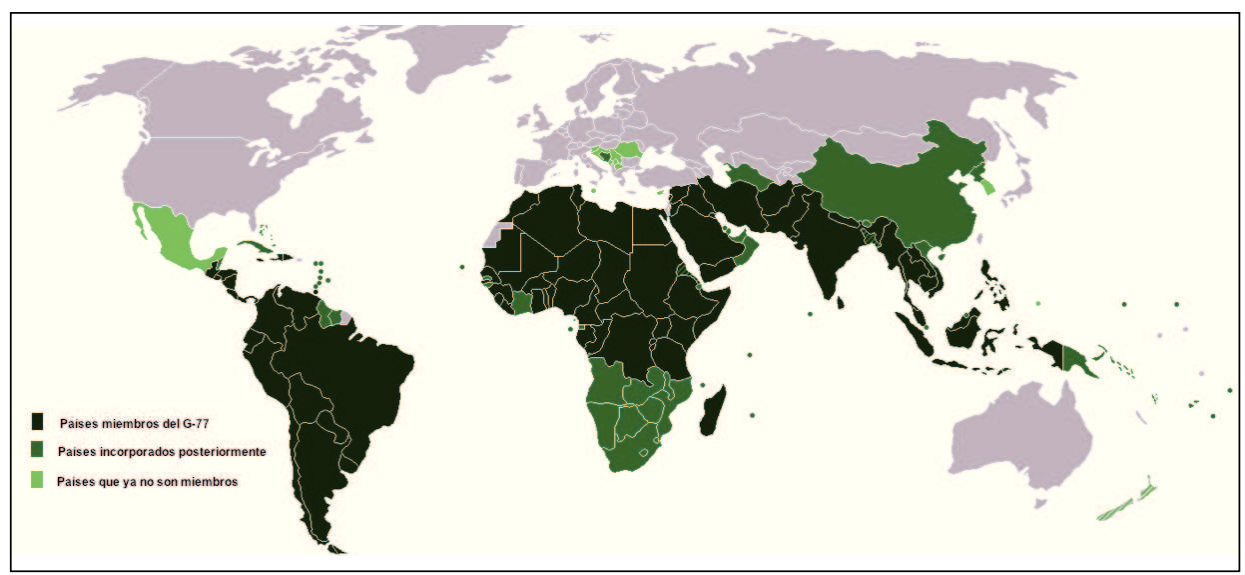

Fonte: http://www.nu.org.bo/snu/paises-miembros-del-g77/ 